\title{
Resurgimiento comunitario ante la nueva realidad socioeconómica
}

\author{
Evaristo Barrera Algarín', José Luís Sarasola Sánchez Serrano² y José Carlos Malagón \\ Siria $^{3}$
}

Recibido: 27 de diciembre de 2016 / Aceptado: 19 de abril de 2017

Resumen. Este estudio analizó las características de los movimientos comunitarios que han cobrado fuerza tras el inicio de la crisis económica en estos últimos años. El trabajo de campo se realizó en cuatro contextos específicos de experiencias comunitarias: Dos de Monedas Sociales, uno de Huertos Urbanos, y otro de Bancos del Tiempo. Hipótesis: Los movimientos de base comunitaria que suponen una ayuda a aspectos económicos de las familias e individuos, toman fuerza en situaciones de crisis económicas, en el contexto de la globalización económica. Metodología: Se hicieron 82 encuestas del Cuestionario ECOM, compuesto de 48 preguntas, y que abarca el análisis de 77 variables. El estudio aportó la conexión entre la situación de crisis y desempleo con la participación en estas actividades; la vinculación de la edad a la participación en contextos distintos; el origen universitario y en desempleo de los participantes; consideración de estas iniciativas comunitarias como una forma de mercado o economía alternativa; vinculación con el principio de bien común; la participación basada en la confianza; y la desconexión entre lo global y lo local dentro de estas iniciativas.

Palabras clave: Economía colaborativa; Bienes Comunes; Globalización; Territorialización; GlobalLocal.

Claves Econlit: H12; P32; P49.

\section{[en] Community resurgence as an answer to the new socioeconomic reality}

\begin{abstract}
This study analyzed the characteristics of community movements which have grown along the economic crisis in recent years. The research was conducted in four specific contexts of community experiences: Two in Social Money, one in Urban Gardens, and the last one in Time's Banks. Hypothesis: community-based movements involving aid economic aspects of families and individuals are becoming stronger in times of economic crisis, in the economic globalization context. Methodology: 82 surveys trough the ECOM Questionnaire, composed of 48 questions and 77 variables. The study provided us the connection between the crisis and unemployment; linking participant's age with the different contexts; unemployed university in the origin to participation; consideration of these community initiatives as a way of market or as an alternative economy; linkage with the principle of commons; participation based on trust; and the disconnection between the global and the local within these initiatives.
\end{abstract}

Keywords: Sharing economy; The Commons; Globalization; Territorialization; Global-Local.

$1 \quad$ Universidad Pablo de Olavide de Sevilla, España Dirección de correo electrónico: ebaralg@upo.es

2 Universidad Pablo de Olavide de Sevilla, España Dirección de correo electrónico: jlsarsan@upo.es

3 Universidad Pablo de Olavide de Sevilla, España

Dirección de correo electrónico: jcmalsir@upo.es 
Sumario. 1. Introducción. 2. Marco teórico. 3. Metodología. 4. Resultados. 5. Conclusiones. 6. Referencias bibliográficas.

Cómo citar: Barrera, E., Sarasola, J.L. y Malagón, J.C. (2017) Resurgimiento comunitario ante la nueva realidad socioeconómica. REVESCO. Revista de Estudios Cooperativos, $\mathrm{N}^{\circ}$ 124, pp. 9-31. DOI: 10.5209/REVE.56131.

\section{Introducción}

El objetivo principal de este artículo es analizar cómo los movimientos de base comunitaria, que suponen una ayuda a aspectos económicos de las familias e individuos, toman fuerza en situaciones de crisis económicas. Para ello se toma como referente empírico un estudio que analizó las características de los movimientos comunitarios que han cobrado fuerza tras el inicio de la crisis económica en estos últimos años. Estos movimientos fueron analizados en diferentes contextos de referencia: Monedas Sociales, Huertos Urbanos, y Bancos del Tiempo. Y que se plantearon como objeto de investigación el analizar las características de los movimientos comunitarios que se desarrollan en relación a la nueva realidad socioeconómica tras el inicio de la crisis económica en estos últimos años. Partimos pues de que los sujetos, cuando se dan situaciones de precariedad económica y social, buscan alternativas al sustento, como por ejemplo, alternativas económicas de base comunitaria, participativa, y alejadas del mercado tradicional. Y que se desarrollan como contrapeso a las consecuencias de la globalización neoliberal.

Pensemos en la realidad socio-económica que nos dibuja un escenario posterior a la quiebra de Lehman Brothers, que marcó el pistoletazo de salida hacia la crisis. Lo que comenzó como una crisis financiera se ha transformado en un mosaico, se ha trasladado al conjunto de la actividad económica, con reflejo en la vida cotidiana de las personas como ponen de manifiesto los diversos estudios e investigaciones que se han realizado tanto en Europa como en España. En el caso concreto de España ${ }^{4}$, en Diciembre de 2015 encontramos una tasa de paro del $20.9 \%$ (recordemos que con anterioridad a la crisis, en Junio de 2006 estuvo en $8.4 \%$, y que incluso durante este periodo de crisis económica se llegó en Marzo de 2013 al 26.9\%). En el contexto de crisis económica, las políticas aplicadas han generado en España un aumento de la desigualdad y la pobreza. Según la OCDE (2015), el 10\% de los españoles con menos ingresos se ha empobrecido a un ritmo del 12.9\% anual. Si nos vamos a datos de la OCDE de 2012 (OCDE 2016a), España se sitúa en el 0.335 del coeficiente $\mathrm{GINI}^{5}$, esto supone que es el noveno país más desigual de la OCDE (36 países), y quinto más desigual de la UE (28 países). Si observamos la Ratio de Pobreza ${ }^{6}$, España sería el séptimo país con

4 Datos obtenidos de la Encuesta de Población Activa (EPA) y del Ministerio de Empleo y Seguridad Social.

5 Para Lizárraga (2013, pág. 67) GINI es el indicador más utilizado y aceptado para cuantificar los niveles de desigualdad de ingresos, que toma valores entre 0 , cuando existe completa igualdad en la distribución del ingreso, y 1, en caso de completa desigualdad.

6 La tasa de pobreza es la proporción del número de personas (en un grupo de edad dado) cuyos ingresos caen por debajo de la línea de pobreza; Tomado como la mitad de la mediana del ingreso familiar de la población total. Sin embargo, dos países con las mismas tasas de pobreza pueden diferir en términos del nivel de ingresos relativo de los pobres (OCDE , 2016b). 
mayor ratio de pobreza (0.140) de los 36 de la OCDE, y el segundo de los 28 de la Unión Europea.

Cuando se habla de crisis económica da la impresión que se trata de un fenómeno que rara vez ocurre; nada más lejos de la realidad. El sistema de producción capitalista ha sufrido crisis cíclicas desde su nacimiento, entre las que hay similitudes y diferencias, pero todas han tenido consecuencias sociales. De hecho, Krugman, Wells y Graddy (2015) nos dicen que las recesiones, o contracciones, son periodos de caída de la economía, en los que la producción y el empleo disminuyen. Estos autores registran un total de 34 grandes recesiones de la economía, desde diciembre de 1854 hasta la actualidad (utilizando datos de la Oficina Nacional de Investigaciones Económicas Norteamericana). Las recesiones "crean gran cantidad de sufrimiento. Los efectos más importantes de una recesión es su efecto sobre la capacidad de los trabajadores para encontrar y mantener empleos" (Krugman, Wells y Graddy 2015: 313). Como hemos descrito con anterioridad, esto se traduce en un aumento del desempleo y un aumento de la desigualdad. Como señala Stiglitz (2012: 355), el uno por ciento más alto dispone de las mejores casas, de la mejor educación, de los mejores médicos y del mejor estilo de vida, pero hay una cosa que aparentemente el dinero no ha conseguido comprar: la constatación de que su destino está ligado a cómo vive el noventa y nueve por ciento restante. Se trata de una lección que a lo largo de la historia, el uno por ciento acaba comprendiendo. Sin embargo, a menudo lo acaba comprendiendo demasiado tarde.

Es en este contexto en el que el estudio analizó cómo las personas empobrecidas utilizan las redes comunitarias que les pueden proveer de recursos. El trabajo de campo se realizó en cuatro contextos específicos de experiencias comunitarias: Dos de Monedas Sociales, uno de Huertos Urbanos, y otro de Bancos del Tiempo. Se partió de la hipótesis de que los movimientos de base comunitaria que suponen una ayuda a aspectos económicos de las familias e individuos toman fuerza en situaciones de crisis económicas. Desde el punto de vista metodológico, se hicieron 82 encuestas del Cuestionario ECOM, compuesto de 48 preguntas, y que abarca el análisis de 77 variables. El estudio aportó la conexión entre la situación de crisis y desempleo de los sujetos, con la participación en estas actividades; la vinculación de la edad a la participación en contextos distintos; el origen universitario y en desempleo de los participantes; consideración de estas iniciativas comunitarias como una forma de mercado o economía alternativa; vinculación con el principio de bien común; la participación basada en la confianza; y la desconexión entre lo global y lo local dentro de estas iniciativas. Todo ello, comprendido en un contexto de globalización económica.

\section{Marco teórico}

Nuestro punto de partida teórico es que existen iniciativas de base local y comunitaria, estructuradas en la participación, autogestión, cooperación, etc., que nacen y se desarrollan como contrapeso a una serie de consecuencias de la globalización neoliberal. 
Una realidad socio-económica inmersa en una situación de crisis no es nada nuevo, sino una etapa cíclica de algo que ya conocemos especialmente desde la década de los 70 con el impulso del neoliberalismo, como ya hemos indicado en las aportaciones de Krugman, Wells y Graddy (2015). Entendemos pues que la actual crisis es un proceso cíclico más del sistema capitalista y que se retroalimenta en un contexto de globalización neoliberal. Para Harvey (2007: 24-26), el Neoliberalismo es un proyecto político para restablecer las condiciones para la acumulación de capital y restaurar el poder de las elites económicas. Harvey sostiene la tesis de que el neoliberalismo funciona bajo la lógica de la 'acumulación por desposesión', que se fundamenta en: La privatización y mercantilización de casi todo, con el fin de abrir nuevos campos a la acumulación de capital (desde servicios públicos hasta formas de propiedad intelectual y formas culturales). Segundo, la financiarización, a tal grado que la desregulación financiera ha hecho de este sistema uno de los principales centros de actividad de redistribución de riqueza de las clases bajas hacia las altas. Tercero, la gestión y la manipulación de la crisis, que implica la difusión de la 'trampa de la deuda' como un instrumento de acumulación de capital. Y, por último, las redistribuciones estatales, que invierten el flujo de la riqueza desde las clases altas hacia las más bajas a través de modelos de privatización y de recortes del gasto público (Harvey, 2007: 175-180).

Técnicamente asistamos a lo que Castel (1997) denominaba "una desestabilización de la sociedad salarial", acompañada de tres fenómenos: degradación de la condición salarial; quiebra del sistema de protección social; y fragilización del vínculo social. Además, según nos indica Hamzaoui, estos fenómenos van acompañados de: un aumento del paro; situaciones de desempleo más prolongados en el tiempo; y el desempleo como causa de exclusión social (2005: 31 y ss.). Para Díaz (2003: 247), y en la misma línea, "los problemas más comunes generados por la globalización son el desempleo, el desplazamiento, la pobreza y desigualdad social, la emigración y la inmigración. Cada uno de estos problemas ha afectado directamente al individuo, a la familia y a la comunidad". Noya y Rodríguez (2010: 99) hablan de un 'determinismo económico', donde "las estructuras y agentes económicos son los pilares fundamentales de todo grupo social; su dinámica está fuera de control, y las otras estructuras sociales se limitan a adaptarse a ella o, si no son capaces de hacerlo, están abocadas a la extinción". Es decir, la globalización neoliberal marca las reglas de todo el resto de la estructura social.

Bauman (2001) llega a afirmar que la globalización introduce un nuevo paradigma de estratificación por sí sola, un nuevo factor de desigualdad dado por la 'movilidad geográfica', por la capacidad para desplazarse y abolir las distancias. La globalización para Bauman es básicamente una deslocalización a gran escala, generadora de desigualdad.

En paralelo a todo lo anterior, la población genera desconfianza hacia los poderes públicos (que en muchas ocasiones se ven como los 'poderes económicos'), lo que genera un problema de legitimidad. Weber (1968) afirma que la legitimidad es entendida como el reconocimiento que la autoridad recibe en el

7 Castel llama "sociedad salarial" al conjunto de medidas destinadas a satisfacer necesidades colectivas: trabajo, salud, vivienda, educación, etc. -estos son "bienes comunes" (Castel, 1997). 
ejercicio de sus funciones dentro de un contexto democrático representativo. Y O'Connor (1973), nos dice que en el estado contemporáneo capitalista se pueden dar dos funciones contradictorias, por un lado, debe crear las condiciones favorables para la acumulación de capital, pero al mismo tiempo ha de legitimarse poniendo en práctica políticas de bienestar en sanidad, educación, atención al desempleo, etc. Cosa que no se está produciendo en la forma que los representados lo necesitan o desean. Mishra (1999) afirma que con la globalización se produe un aumento de la desigualdad que hace que aumenten las expectativas de los ciudadanos respecto al Estado de Bienestar, pero al mismo tiempo, esta misma globalización, anula la capacidad redistributiva de estos mismos Estados de Bienestar para atender esta demanda. Mishra plantea la posibilidad de una 'desligitimación por sobredemanda' (Noya y Rodríguez, 2010: 240). En estas cuestiones, Offe (1996) cuando teoriza sobre crisis de legitimidad desde una perspectiva económica, llega a la conclusión de que esta se produce cuando se prima la lógica de la acumulación sobre la prestación de servicios de bienestar. Justamente lo que está ocurriendo. No es de extrañar que en este contexto triunfe un libro titulado "Indignaos" (Hessel 2011). En el mismo se expresa que la peor de las actitudes es la indiferencia, identificando dos grandes desafíos: 1) la inmensa distancia que existe entre los muy pobres y los muy ricos, que no para de aumentar; y 2) el cumplimiento de los derechos humanos en todo el planeta.

Estas situaciones de dificultad económica hacen que las personas busquen alternativas. De hecho, Barkin (2001: 184) nos dice que estas alternativas surgen por la incapacidad demostrada de la economía contemporánea, y su fracaso generador de una profunda polarización social. Barkin y Baron (2005: 175), llegan a afirmar que el empleo proletario ya no es viable y que el retorno a las formas tradicionales de cooperación, organizadas en torno a los mecanismos de gestión de los ecosistemas, podría ofrecer una mayor seguridad y una mejor calidad de vida. "La gente está encontrando maneras de fortalecer sus comunidades", para garantizar que sus familias puedan sostenerse. Precisamente el fracaso del modelo económico y la radicalización del mismo, es el que genera que emerjan sus opositores, y en este caso, movimientos económicos alternativos y de base comunitaria.

Siguiendo a Williamson, Imbroscio y Alperovitz (2002) podemos ver también cómo las iniciativas locales y comunitarias emergen en el contexto de la globalización neoliberal. Para los autores, la comunidad sufre una 'triple amenaza': primero, la globalización aumenta la volatilidad económica y la inseguridad laboral a medida que las empresas se mueven o amenazan con moverse; segundo, los estados y ciudades compiten entre sí en la creación puestos de trabajo, lo que supone una competición para ofrecer las mayores exenciones fiscales a una corporación; por último, la expansión suburbana socava tanto a las comunidades urbanas como rurales. Para estos autores, las políticas públicas serían las que pueden ayudar a lograr la estabilidad local. Nos referimos a la inversión pública y en lo público. De hecho llegan a argumentar 15 políticas públicas eficaces en la estabilización del empleo. También traen como ejemplo cinco formas de fortalecer las iniciativas locales (incluidas las monedas sociales), seis medidas de políticas locales o estatales para apoyar a las comunidades (como la rendición de cuentas 
corporativa para los receptores de subsidios), y ocho tipos de empresas estatales y municipales (Williamson, Imbroscio y Alperovitz, 2002).

Estas alternativas no necesariamente tienen que fundamentarse en la economía tradicional y controlada, ni tampoco al amparo de los representantes políticos o de la Administración. Tal es el caso de la economía social, el corporativismo, bancos del tiempo, la organización y el desarrollo de comunidades basadas en la autogestión y el desarrollo sostenible. Hoy lo denominaríamos "economía colaborativa" o "consumo colaborativo" (Rauch y Schleicher 2015; Botsman y Rogers 2010; Algar 2007). Además se conecta con un deterioro de la calidad democrática, de ahí que uno de los gritos más coreados de los movimientos sociales sea el de "no nos representan". No es de extrañar debido a la indignación que provocan las rebajas de salarios, recortes en los presupuestos públicos, con especial incidencia en educación, salud y servicios sociales y más privatizaciones y mercantilización de dichos servicios. Es decir, el traspaso de los bienes comunes que han costado años y años de lucha a la clase obrera a manos privadas con ánimo de un lucro desmesurado. Como señala Sennett (2006: 44), lo que buscan los reformadores del estado de bienestar es más iniciativas y empresas personales: bonos para la educación, cuentas de ahorro para hacer frente a la vejez y a la atención médica y una seguridad social personal manejada como empresa consultora.

En este contexto social adverso, y como venimos diciendo, se generan alternativas y nuevas formas de sustento y actividad económica que enlazan con un resurgimiento de lo comunitario. Un fenómeno comunitario que no es nuevo (aunque sus formas se acomoden a los tiempos actuales). Las situaciones socioeconómicas precarias han generado desde siempre movimientos comunitarios de autoayuda que algunas profesiones como el Trabajo Social tienen bien documentadas y conocen desde sus cimientos. Es el caso de los 'settlements houses' o 'settlement movement' que tuvo su origen en la Toynbee Hall (Miranda 2004: 164) fundada por Barnett en 1884 en un barrio obrero londinense. La casa era al tiempo una residencia de estudiantes universitarios, que a través de un voluntariado social se comprometían a realizar actividades de ayuda, promoción social, educación, higiene.... fomentando la organización social comunitaria. La idea se extendió rápidamente, y en 1900 ya estaba presente, no sólo en Reino Unido, sino en más de 100 ciudades en Estados Unidos (Miranda 2004: 168). Según la Encyclopedia of Social Work (1999), el movimiento de los settlements había nacido como respuesta al capitalismo industrial. De entre ellos el más conocido fue la "Hull House" de Chicago fundada por J. Addams (trabajadora social que obtendría el Premio Nobel de la Paz en 1931 por sus reivindicaciones sociales). Para Davis ${ }^{8}$ estas iniciativas se sustentaban no solo en la creencia de que era necesario transformar las sociedades urbanas (especialmente en su lucha contra las malas condiciones sociales) sino en que además era posible. Hoy día encontramos iniciativas similares en muchos puntos del planeta, como por ejemplo en la Residencia Universitaria Flora Tristán ${ }^{9}$ donde encontramos también las 3 "R"

Citado por Miranda (2004, pág. 172).

Perteneciente a la Universidad Pablo de Olavide. Más información en https://www1.upo.es/floratristan/proyecto-social/. 
que se daban en la Hull House: Residencia, Investigación y Reforma (Residence, Research and Reform).

En los contextos sociales que analizamos en este artículo, surgen iniciativas sociales centradas en lo comunitario (en lo local, en el barrio...). Noya y Rodríguez nos dicen que precisamente la globalización económica refuerza las identidades locales y nacionales, como contrarespuesta. Este retorno a las identidades culturales y locales se puede atribuir a que la globalización es básicamente un proceso económico, "basada en una lógica mercantil cada vez más fría y abstracta, que empuja a las personas a buscar la calidez y las emociones asociadas a las identidades" (Noya y Rodríguez, 2010: 25). No son pocos los referentes científicos y académicos que se acercan a este fenómeno. Barkin desde la Economía Ecológica, analiza las alternativas socioeconómicas de base local sobre el principio de "autosuficiencia", la "solidaridad económica" y las redes comunitarias. Para este autor, estas iniciativas cumplirían las siguientes características: Son autónomas; autosuficientes; proponen una diversidad productiva; y suponen una gestión sostenible de los recursos (2009: 372). Por otro lado, fomentan la participación social, y la acción local (Barkin y Barón 2005: 175). En un estudio publicado por Fleischman, Boenning, Garcia-Lopez, Mincey, Schmitt-Harsh, Daedlow, Lopez, Basurto, Fischer y Ostrom (Fleischman, y otros, 2010) estudiando 5 comunidades a lo largo de 15 años, nos dicen que son claves de la organización comunitaria la forma y la elección colectiva de reglas; el liderazgo y el forma empresarial; la vigilancia y sanción; los valores económicos; número de sujetos que se admiten para participar, y la gestión del capital social . Para Ostrom (2010: 155) las principales variables estructurales que afectan a los niveles de cooperación son fundamentalmente la reputación, la confianza y la reciprocidad. Pero esta misma autora, en otros trabajos (Ostrom 2003:. 239), y basándose en distintos estudios empíricos entiende que es más fácil en algunos casos la gestión de los bienes privados que los comunales. Aunque como indicamos, son numerosas las iniciativas de producción social y gestión participativa del hábitat que funcionan por encima de la propiedad privada o las formas tradicionales de mercado. Ortiz (Ortiz 2010) pone como ejemplo a tres experiencias concretas dedicadas durante más de 30 años a la producción y gestión participativa del hábitat: La Cooperativa Unión de Palo Alto, Barrio Cananea y Conjunto Autogestionario el Capulín. Pueden complementar la visión de Ostrom, las aportaciones de Putnam (2000), en su Teoría del capital social. Aquí Putnam distingue entre dos clases de capital social: el capital vínculo y el capital puente. El vínculo se da cuando la persona se socializa con otros semejantes: de la misma edad, raza, religión, etc. Pero para ir más allá son necesarios otros tipos de vínculo, el que tiende puentes. Los puentes se tienden cuando se crean lazos con gente distinta. Putnam afirma que los que cuentan con ambos tipos de vínculo se fortalecen mutuamente. Para Putnam, el declive del capital vínculo produce el declive en el capital puente, lo que desencadena tensiones étnicas y religiosas. Las iniciativas sociales que este estudio analiza, se sustenta principalmente, entre otras cuestiones en la conexión de su capital social, con la utilización de lazos puente. Ahondando en estas cuestiones, también traemos aquí el estudio de investigación sobre el papel de los diferentes tipos de empresas en la creación de la confianza social (Sabatini, Modena y Tortia, 2014). Este estudio, basándose en un conjunto de datos recogido a través de la 
administración de un cuestionario a una muestra representativa de la población de la provincia italiana de Trento, afirma que las cooperativas son el único tipo de empresa donde el entorno de trabajo fomenta la confianza social de los trabajadores. Para Borzaga, Depedri y Tortia se subestima el potencial de crecimiento, el peso y el papel de las empresas cooperativas y sociales. Estas empresas y cooperativas sociales se sustentan en objetivos diversos, desde la apropiación puramente privada (lucro), hasta los objetivos de beneficio público apoyados por preferencias altruistas (Borzaga, Depedri y Tortia, 2010, pág. 1). De hecho, algunos autores como Bretos y Marcuello (2017), argumentan que en los últimos años aparecen iniciativas que generan desarrollo económico sostenible y una mayor cohesión social en el contexto de la globalización neoliberal. Se están refiriendo también a las cooperativas y a sus potencialidades en un mundo globalizado.

Aquí cobra sentido la Teoría del Decrecimiento de Latouche (2007) que puede dar cobijo a estas iniciativas sociales económicas alternativas. Esta teoría supone una corriente de pensamiento político, económico y social favorable a la disminución regular controlada de la producción económica, con el objetivo de establecer una nueva relación de equilibrio entre el ser humano y la naturaleza, pero también entre los propios seres humanos. La cuestión es que rechaza el objetivo de crecimiento económico en sí del liberalismo y el productivismo, proponiendo conceptos alternativos como: Revaluar (poner en alza valores locales, de cooperación y humanistas); Reconceptualizar; Reestructurar (aplicando una nueva escala de valores); Relocalizar (buscando la autosuficiencia); Redistribuir; Reducir (consumismo); y Reutilizar y Reciclar.

Díaz (2003), cuando define los elementos implicados en el desarrollo de la participación en la comunidad, destaca especialmente 5 tipos: Una adecuada información para poder participar en ella; la existencia de canales adecuados para poder participar en las iniciativas; la formación y educación en determinados valores que sirven a esas mismas iniciativas; una motivación suficiente para querer seguir participando o incluso para invitar a participar a otros; y una buena coordinación que asegure el funcionamiento de las mismas. "De manera que las intervenciones a desarrollar tengan un carácter ecológico, y dejen de lado las aspiraciones e intereses puramente individualistas para dotarlas de un carácter solidario y comunal" (Díaz 2003: 245).

\section{Metodología}

Se realiza estudio de investigación cuyo objeto de investigación se centró en analizar las características de los movimientos comunitarios que se desarrollan en relación a la nueva realidad socioeconómica tras el inicio de la crisis económica en estos últimos años. Es decir, de cómo se producen respuestas de base local y comunitaria ante las situaciones adversas en un contexto de globalización económica. Este estudio se sustentó en una hipótesis principal: Los movimientos de base comunitaria que suponen una ayuda a aspectos económicos de las familias e individuos, toman fuerza en situaciones de crisis económicas en el contexto de la globalización económica. 
El estudio de tipo cuantitativo, descriptivo, se realizó utilizando el Cuestionario ECOM, diseñado por el grupo de investigación oficial en Trabajo Social y Políticas Sociales (PAIDI Sej-452), compuesto de 48 preguntas, y que abarca el análisis de 77 variables (en su mayoría de tipo ordinal). En términos estadísticos, estas variables cumplen las características que se describen en el anexo I (ver Anexo I). En total se administraron 82 cuestionarios en cuatro contextos específicos de experiencias comunitarias, que son los siguientes:

Primero, "La Oliva", moneda social en la zona Sur de Sevilla. Se trata de una moneda compartida por los vecinos del Barrio de la Oliva, situado en la Zona del Polígono Sur de Sevilla. Este barrio data de los años 70, tiene una población de unos $5940^{10}$ habitantes. La moneda social es una iniciativa populosa y bien acogida por su vecindario.

Segundo, "Huertos Urbanos" de la Universidad Pablo de Olavide ${ }^{11}$. Los huertos de la Universidad Pablo de Olavide ocupan un terreno junto al edificio Celestino Mutis de 2.000 metros cuadrados, divididos en 55 parcelas de 25 o 50 metros cuadrados cada una. Hoy en día es un proyecto consolidado en el que participan estudiantes, personal de administración y servicios y profesorado, quienes disfrutan de los beneficios sociales, culturales, económicos, educativos y medio ambientales que generan este tipo de instalaciones, características que lo convierten en una actividad muy demandada e idónea para todos los públicos.

Tercero, "Asociación Bancos del Tiempo". Proyecto del Ayuntamiento de Sevilla ${ }^{12}$, para cualquier persona mayor de 18 años de la ciudad. Esta iniciativa se articula desde la Zona de Trabajo Social correspondiente a los Distritos Nervión y San Pablo-Santa Justa. Por tanto es una iniciativa del Área de Familia, Asuntos Sociales y Zonas de Especial Actuación del Ayuntamiento de Sevilla que cuenta con la colaboración de la Junta de Andalucía.

Y cuarto, la "Moneda Social" de Alcalá de Guadaíra ${ }^{13}$. Surge a partir de un movimiento ciudadano independiente de personas comprometidas con la sociedad, que pretende generar una red solidaria de economía alternativa y consumo responsable basada en la confianza y el apoyo mutuo de sus participantes. Entienden el dinero sólo como una herramienta para el intercambio en la comunidad. La moneda social de Alcalá de Guadaíra se llama 'Chábir'.

Los cuestionarios quedaron repartidos según se explica en la Tabla 1. Estos cuestionarios fueron respondidos por personas participantes en cada una de las iniciativas.

10 Datos censales del Ayuntamiento de Sevilla: http://web.archive.org/web/http://www.sevilla.org/ayuntamiento/organizacionmunicipal/distritos/copy of sur/datos-censales-del-distrito-sur.

11 Universidad Pablo de Olavide: https://www.upo.es/diario/institucional/2016/10/abierto-el-plazo-para-solicitarlas-parcelas-disponible-de-los-huertos-ecologicos-y-sociales-de-la-upo/.

12 Banco del Tiempo del Ayuntamiento de Sevilla: http://www.sevilla.org/ayuntamiento/competenciasareas/area-de-bienestar-social-y-empleo/a-servicio-de-intervencion-de-servicios-sociales/prestacionesprogramas-y-actuaciones/banco-del-tiempo.

13 Moneda Social de Alcalá de Guadaira: https://plus.google.com/101661643620771857347. 
Tabla. 1. Distribución de los cuestionarios por zonas/ámbitos.

\begin{tabular}{|c|c|c|c|c|c|}
\hline \multicolumn{2}{|c|}{} & Frecuencia & Porcentaje & Porcentaje válido & Porcentaje acumulado \\
\hline \multirow{4}{*}{ Válidos } & La Oliva & 24 & 29,3 & 29,3 & 29,3 \\
\cline { 2 - 6 } & Huertos Urbanos & 18 & 22,0 & 22,0 & 51,2 \\
\cline { 2 - 6 } & Banco del Tiempo & 18 & 22,0 & 22,0 & 73,2 \\
\cline { 2 - 6 } & $\begin{array}{l}\text { Moneda Social de } \\
\text { Alcalá }\end{array}$ & 22 & 26,8 & 26,8 & 100,0 \\
\hline & Total & 82 & 100,0 & 100,0 & \\
\hline
\end{tabular}

Fuente: Elaboración propia.

El cuestionario fue administrado cara a cara a través de encuestadores adiestrados para la tarea (19 colaboradores). El trabajo de campo se desarrolló durante el periodo 2014-2015.

El estudio se realizó siguiendo las directrices éticas internacionales y profesionales pertinentes. Los investigadores se basaron en el Código Deontológico del Trabajo Social (amparados por el Consejo General de Trabajo Social y la Federación Internacional de Trabajadores Sociales) y atendiendo a las directrices de la Ley Orgánica 15/1999, de 13 de diciembre, de Protección de Datos de Carácter Personal.

La muestra presentaba las siguientes características: Son mayoritariamente mujeres $(63.4 \%)$. El $53.6 \%$ son personas con edades entre 35 y 59 años. En referencia a la edad, las personas más mayores, participan más en el "banco del tiempo" que en otros contextos (de hecho el $66.7 \%$ de los encuestados son mayores de 60 años). La mayoría son personas casadas (42.7\%), pero en el caso de bancos del tiempo, donde hay más mayores, encontramos al $83.4 \%$ de todas las viudedades de la muestra. El régimen de tenencia de la vivienda es mayoritariamente en propiedad (64.6\%). Sobre la formación, obtenemos una muestra muy heterogénea (ver tabla 2). Nos llama la atención que el $24.4 \%$ son personas con estudios universitarios. 
Tabla. 2. Nivel de formación

\begin{tabular}{|l|r|r|r|r|r|}
\hline \multicolumn{2}{|l|}{} & Frecuencia & Porcentaje & \multicolumn{1}{c|}{$\begin{array}{c}\text { Porcentaje } \\
\text { válido }\end{array}$} & $\begin{array}{c}\text { Porcentaje } \\
\text { acumulado }\end{array}$ \\
\hline Válidos & $\begin{array}{l}\text { Menos de 5 años de } \\
\text { escolarización }\end{array}$ & 2 & 2,4 & 2,4 & 2,4 \\
\cline { 2 - 6 } & Educación primaria & 13 & 15,9 & 15,9 & 18,3 \\
\cline { 2 - 6 } & ESO & 7 & 8,5 & 8,5 & 26,8 \\
\cline { 2 - 6 } & FP de grado medio & 10 & 12,2 & 12,2 & 39,0 \\
\cline { 2 - 6 } & Bachillerato & 13 & 15,9 & 15,9 & 54,9 \\
\hline & FP de grado superior & 17 & 20,7 & 20,7 & 75,6 \\
\hline & $\begin{array}{l}\text { Arquitectura Técnica, } \\
\text { Diplomatura }\end{array}$ & 5 & 6,1 & 6,1 & 81,7 \\
\cline { 2 - 6 } & $\begin{array}{l}\text { Grado, Arquitectura, } \\
\text { Ingeniería } \\
\text { Licenciatura }\end{array}$ & 13 & 15,9 & 15,9 & 97,6 \\
\cline { 2 - 6 } & $\begin{array}{l}\text { Estudios de Posgrado, } \\
\text { Máster, Doctorado }\end{array}$ & 2 & 2,4 & 2,4 & 100,0 \\
\cline { 2 - 6 } & $\begin{array}{l}\text { Total } \\
\end{array}$ & 82 & 100, & 100,0 & \\
\hline
\end{tabular}

Fuente: Elaboración propia.

Si bien el 51.9\% de la muestra nos dice no tener cargas familiares, detectamos que aquellas familias que tienen a su cargo hijos menores, se concentran en exclusividad en las 2 monedas sociales analizadas (Alcalá y La Oliva) y en los huertos urbanos, contextos relacionados con la provisión de productos de consumo, más que con la provisión de servicios. Si atendemos a las ramas profesionales de origen de los encuestados, podemos ver que destacan las personas que provienen del campo de socio-sanitario (actividades sanitarias y de servicios sociales) en un $14.5 \%$ (ver gráfico 1). En cuanto a su situación económica, el $49.3 \%$ de la muestra presenta dificultades económicas, y el $14.7 \%$ nos dice depender económicamente de otras personas. Tan sólo el 36\% asegurar llegar bien a fin de mes. En líneas generales el $50 \%$ tiene ingresos inferiores al SMI ${ }^{14}$. Sobre este aspecto vemos que hay una diferencia intergeneracional: El $50 \%$ de las personas con ingresos superiores al SMI son mayores de 60 años, mientras que el $68.6 \%$ de aquellos que no llegan al SMI, son personas de entre 18-49 años (el factor "pensión" se presenta

14 Salario Mínimo Interprofesional: 648,60€ en el momento de la encuesta. 
como un mejor garante de ingresos que el factor "trabajo"). En términos de género, las mujeres presentan peor situación en cuanto a sus ingresos (suponen el $71.4 \%$ de las personas con ingresos inferiores al SMI).

Sobre la situación laboral, nuestro estudio detecta que el $70.5 \%$ de la muestra presenta desempleo, no empleo o irregularidad de ingresos (trabajos esporádicos). Cuando analizamos su situación laboral en el tiempo, obtenemos que los que trabajaban hace 3 años eran el $52.6 \%$, y que ahora se ha reducido hasta el $29.5 \%$; esto supone una destrucción de empleo en este colectivo de un $23.1 \%$ en 3 años. Sobre esto, observamos que el $37.3 \%$ de la muestra ha mantenido en estos años una situación de desempleo, a los que hay que sumar un $24 \%$ que ha caído en el desempleo (sólo encontraron un empleo un $5.3 \%$ de la muestra).

Gráfico. 1. Rama de actividad profesional

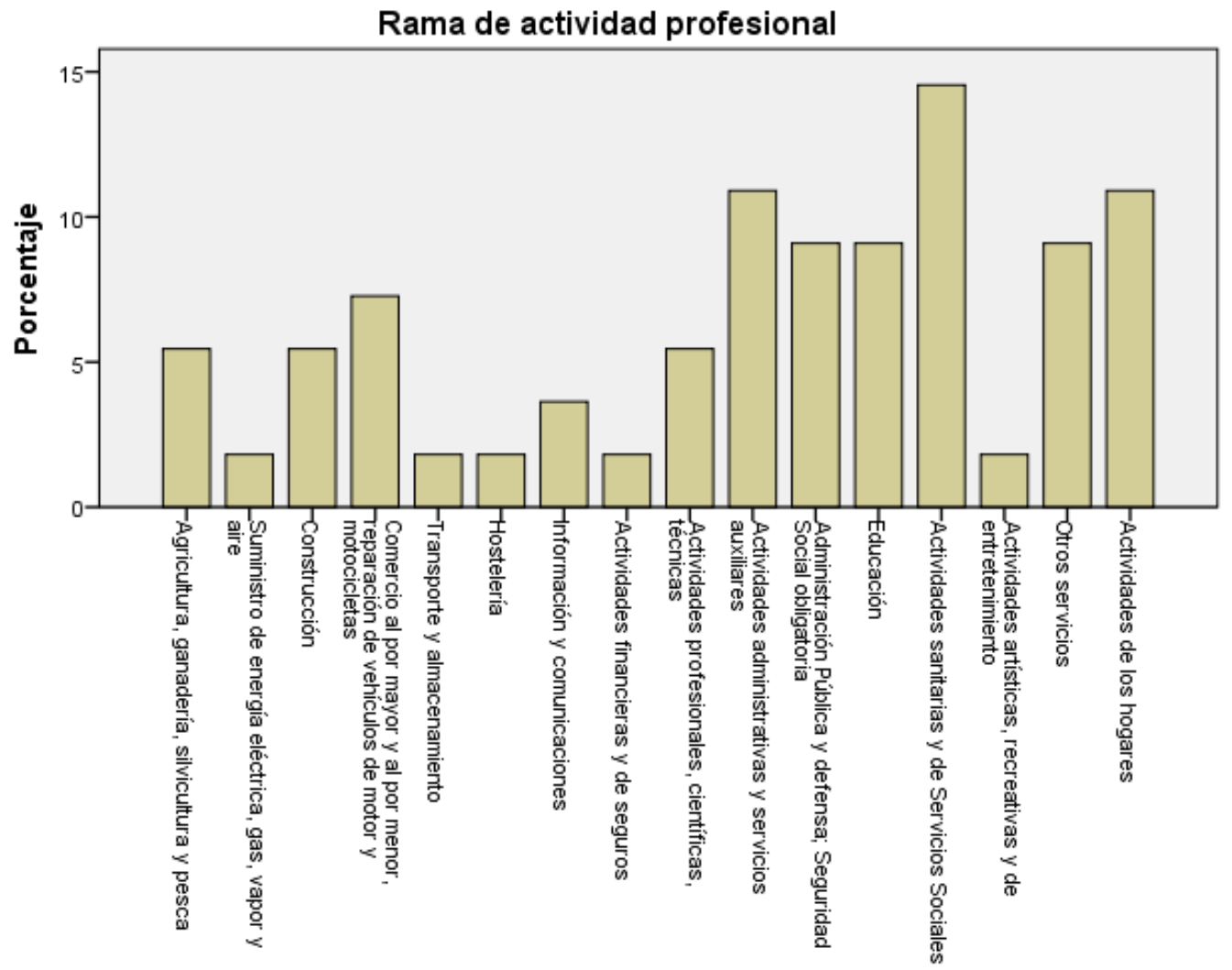

Fuente: Elaboración propia.

\section{Resultados}

Para poder analizar los resultados, ordenaremos estos según distintos apartados: 
En referencia a la vinculación con las actividades comunitarias, el $46.2 \%$ de la muestra son personas que participan a su vez en otras actividades comunitarias. De hecho, $46.3 \%$ son personas que nos dicen estar vinculadas como "voluntarias" en otros contextos. Esta pluri-actividad se da con mayor énfasis en los sujetos de mayor edad (50-69) que en los más jóvenes, y curiosamente, dentro del sector de personas desempleadas, $63.6 \%$ nos indican que participan únicamente en esa actividad.

Sobre la frecuencia de uso de la actividad comunitaria, se destaca que el $48.8 \%$ de la muestra lo hace de manera esporádica. Los jóvenes entre 18-34, y los mayores de 60 en adelante, son los más asiduos. De los contextos comunitarios analizados, el "banco del tiempo" es el que presenta una mayor asiduidad en sus participantes (el $62.5 \%$ lo utiliza de manera frecuente. El $57.5 \%$ de toda la muestra suele permanecer en la actividad hasta el final de la misma.

Sobre la manera en que conoce y accede a la actividad comunitaria, el $67.1 \%$ indica conocerla desde hace bastante tiempo (más de 7 meses), a través de: una amistad (28\%), a través de un familiar (15.9\%), a través de una entidad o asociación (13.4\%) o bien las conoce de siempre (13.4\%).

Sobre la opinión que se tiene de la actividad en la que participan, esta es positiva o muy positiva en un $90.1 \%$ de los encuestados. Pero si se les pregunta sobre la percepción que la sociedad tiene sobre estas actividades, esta sigue siendo positiva o muy positiva en su mayoría, pero se parecía una disminución cualitativa de la misma (esto queda reflejado en la tabla 3 ). Como podemos ver, la opinión que se tiene de estas actividades es bastante positiva. Para confirmarlo, y a través de un análisis Likert con 12 ítems (queda descrito en el gráfico 2), se obtiene una puntuación de 5.230 sobre 6: esto implica que la actividad la entienden como: satisfactoria, recompensante, emocionante, interesante, ilusionante, divertida, desafiante, importante, entretenida, flexible, gratificante y útil.

Tabla. 3. Opinión sobre la actividad comunitaria y opinión percibida desde la sociedad.

\begin{tabular}{|l|r|l|r|r|r|}
\hline \multicolumn{2}{|l|}{$\begin{array}{l}\text { Opinión general sobre estas } \\
\text { actividades }\end{array}$} & $\begin{array}{l}\text { Opinión sobre la percepción } \\
\text { de la sociedad sobre estas } \\
\text { actividades }\end{array}$ & $\begin{array}{l}\text { Diferencia entre ambas } \\
\text { percepciones }\end{array}$ \\
\hline Negativa & 2,5 & & 9,9 & Aumenta & 7,4 \\
\hline Positiva & 44,4 & & 59,3 & Aumenta & 14,9 \\
\hline Muy positiva & 53,1 & & 30,9 & Disminuye & $-22,2$ \\
\hline Total & 100 & 100 & & \\
\hline
\end{tabular}

Fuente: Elaboración propia. 
Gráfico. 2. Descripción positiva de la actividad comunitaria a través de análisis Likert.

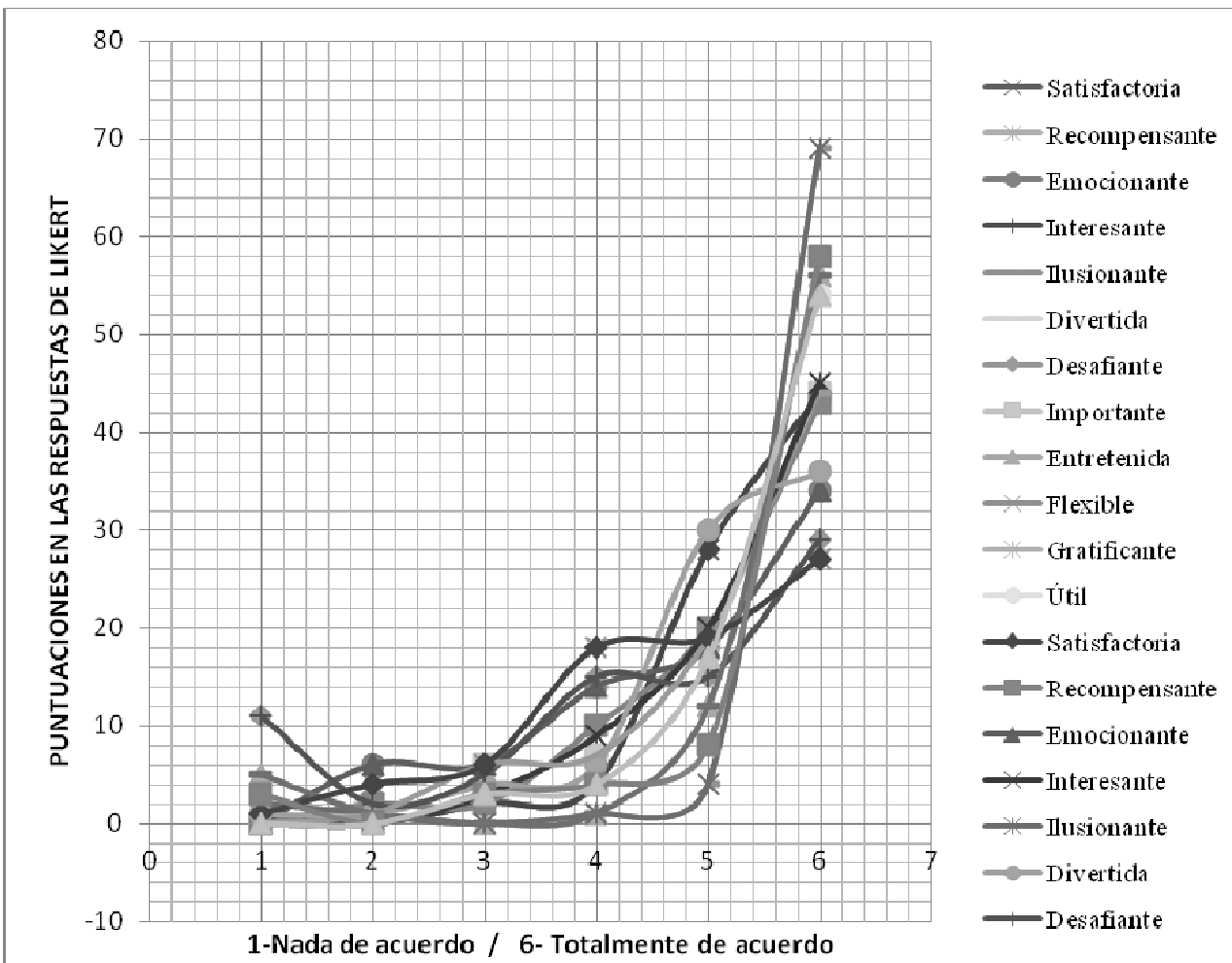

Fuente: Elaboración propia.

En este estudio se ha detectado un alto nivel de "criticismo" por parte de quienes participan en estas actividades. Esto se refleja en varios aspectos: El 80.2\% considera que no hay adecuada información para participar; el $77.9 \%$ opina que los canales de participación no son los adecuados; el $92.5 \%$ en nos dice que no existe motivación para seguir participando, o para invitar a participar a otros; el $87.7 \%$ afirma que no hay una buena coordinación para su funcionamiento; o el $88.9 \%$ que nos dicen que los horarios no son los adecuados.

Observamos que es establece una conexión a la participación en estas actividades en relación con la cercanía: el 54.9\% nos hablan de que residen muy cerca de la actividad (el $53.8 \%$ reside en el mismo barrio). Un $42.7 \%$ No reside cerca, pero no le supone un problema para poder participar.

Sobre la relación que guardan estas actividades comunitarias con su contexto social y el sistema de valores, los participantes no ven con claridad estas relaciones. El $96.3 \%$ nos dice que estas actividades no forman ni educan en determinados valores. El $81.7 \%$ afirman que no responden a un tipo de ideología o forma de entender el mundo concreto. El $82.7 \%$ entiende que no suponen una respuesta alternativa a las cuestiones económicas dominantes, o el $80.2 \%$ que no suponen una forma de contestación a las líneas políticas dominantes. En cambio, 
cuando se les pregunta sobre la relación de estas actividades con la actual situación de desempleo, el $62 \%$ nos afirma que existe una relación directa.

Pero si se les formula las preguntas de otra forma, obtenemos otros resultados. A la pregunta de si se siente identificado con los valores que representan estas actividades, el $96.2 \%$ de la muestra nos dice que sí; el $96.1 \%$ se siente satisfecho de estar vinculado a estas actividades; y el $98.8 \%$ ha recomendado en alguna ocasión a otra/as personas que participen en estas actividades. El 79.7\% considera que existen unos valores compartidos por los implicados y participantes. Pero en cambio, el 59.5\% considera que no existen unos intereses compartidos por los implicados y participantes (especialmente sensibles a este aspecto los tramos de edades entre 35-59 años). Apreciamos una distinción clara entre valores comunes e intereses comunes. Además, aun que el $50.6 \%$ de la muestra considera que existe deseo de extender esta experiencia y formar a otros en ella, un $49.4 \%$ nos dice lo contrario (de estos, el tramo de edad de entre 35-59 se posicionan mayoritariamente en el no).

Sobre el "sentimiento de pertenencia", el 93.6\% considera que estas iniciativas fomentan un sentimiento de pertenencia a una comunidad, además, el $93.6 \%$ también considera que estas iniciativas fomentan el estrechamiento de lazos comunitarios.

Analizando la dimensión económica de estas actividades comunitarias alternativas, el $52.5 \%$ de los encuestados entiende que se trata de una forma de "mercado", pero el $48.8 \%$ lo concreta más como una forma de "mercado alternativo al hegemónico". Cuando se les pregunta si estas actividades generan beneficios económicos, consideran que no un $57.1 \%$, pero si en un $40.3 \%$. Esta percepción de actividad generadora de beneficios económicos se centra en las monedas sociales y no tanto en huertos urbanos o bancos del tiempo. El tramo de edad de entre 50-60 años ven claramente el beneficio económico de unos pocos y no de la generalidad.

Si analizamos a los agentes de control, los encuestados nos indican que nadie controla la actividad de que se trate (69.3\% de la muestra).

Dentro del estudio se le proponía a los entrevistados indicarnos si la actividad podía ser o no una respuesta ante el fracaso de otros agentes (Mercado, Estado o iniciativas sociales). En un $88.2 \%$ nos dicen que no son una respuesta ante el fracaso de las iniciativas sociales; pero cuando preguntamos si surge como respuesta al fracaso del mercado, el $27.6 \%$ de la muestra dice que sí, y en el caso del Estado, el porcentaje se eleva hasta el $42.1 \%$. Los participantes en estas actividades ven de forma más clara el fracaso del Estado que el del Mercado.

Otras características de las actividades comunitarias analizadas son las siguientes: El $84 \%$ no considera la iniciativa como autónoma; el $82.4 \%$ considera que la iniciativa no es autosuficiente; el $71.7 \%$ entiende que no existe una diversificación productiva en la iniciativa; el 78.7 \% considera que la iniciativa no supone una gestión sostenible de los recursos; el $92.4 \%$ considera que la iniciativa no implica un aumento de la participación social de forma directa; al igual que tampoco considera que la iniciativa aumente la acción local (90.9\%). Tan sólo el $22.1 \%$ considera estas iniciativas como respuesta contra la polarización social y económica; y el $35.4 \%$ considera estas iniciativas como respuesta ante el empeoramiento de las condiciones ambientales. Tal y como indicábamos con 
anterioridad, se observa un alto nivel de "criticismo" dentro del colectivo de participantes en estas actividades.

El 39\% de la muestra considera que estas actividades comunitarias son una respuesta para superar la actual crisis. Se destaca especialmente en los huertos urbanos, donde se lo consideran un $61.1 \%$ de sus participantes, y en el banco del tiempo, donde lo consideran el 53.3\%. Ambos contextos son de provisión de servicios y de alimentos.

Sobre el concepto del "bien común, el 93.8\% nos dice que los intereses que dan lugar a estas iniciativas son intereses comunes o grupales (de una generalidad); y el 97.5\% afirma que los esfuerzos que posibilitan estas iniciativas también son comunes o grupales (en el mismo sentido que lo anterior).

En relación a la capacidad de influencia de estas actividades en la sociedad, el $75 \%$ de la muestra considera que estas actividades tienen capacidad de influencia en la Administración Pública. Sin embargo, el 54.7\% nos dicen que estas actividades no tienen capacidad de influencia en la Empresa.

El $61.1 \%$ de los participantes perciben que la administración pública muestra indiferencia frente a estas iniciativas.

Detectamos una disfunción "global-local": La muestra no observan la conexión entre lo global y lo local. El 50.7\% considera que estas iniciativas están influenciadas por políticas sociales y económicas locales. En contraposición, el $89.9 \%$ Considera que estas iniciativas no están influenciadas por políticas sociales y económicas nacionales, y el $87 \%$ que no están influenciadas por políticas sociales y económicas internacionales.

\section{Conclusiones}

A partir del desarrollo de los datos anteriormente expuestos, queremos destacar la existencia de iniciativas de base local y comunitaria, estructuradas en la participación, autogestión, cooperación, etc., que nacen y se desarrollan como contrapeso a una situación de crisis económica, en el contexto de la globalización neoliberal. Este fenómeno los hemos observado en multitud de elementos que nos han aportado los datos empíricos.

El hecho de que estas iniciativas sean una respuesta ante la situación de crisis en un contexto de globalización neoliberal, se expresa especialmente en la relación con la situación de precariedad económica (vulnerabilidad) y/o desempleo de sus participantes. La situación de desempleo $(70.5 \%)$ de la muestra, asociada también a una precariedad y vulnerabilidad económica de la población estudiada (49.3\%), con situaciones de ingresos por debajo al SMI, y donde incluso los pensionistas (Población mayor de 60) se encuentra en niveles económicos mejores que la población más joven. Esto nos lleva a plantearnos nuevas preguntas ¿Si esta población tuviese empleo, se participaría igual en estas actividades comunitarias? El $62 \%$ de la muestra entiende que existe una relación directa entre su situación de desempleo y la participación en estas actividades comunitarias. Pensemos que a tenor de los resultados obtenidos, es especialmente la población en desempleo la que no es pluriparticipativa, es decir, se vincula su participación a una sola actividad comunitaria. Esta actividad suele ser en contextos de provisión de 
servicios y de alimentación (Bancos del tiempo y Huertos Urbanos) especialmente. Se vinculan a contextos comunitarios como respuesta a la crisis, para satisfacer necesidades que de otra forma es más difícil o incluso imposible satisfacer. Apoyando esta idea son los datos que nos indican que estos contextos que generan productos y servicios para el consumo de primera necesidad es donde más presencia hay de sujetos con cargas familiares. Vemos una relación directa de los contextos de crisis capitalista y el impacto que estos generan en los seres humanos, que quedaron expuestos por Krugman, Wells y Graddy (2015), Stiglitz (2012), Harvey (2007), Castel (1997), Hamzaoui (2005), los problemas que generan la globalización expuestos por Díaz (2003), o del impacto que genera el 'determinismo económico' expuesto por Noya y Rodríguez (2010), y las desigualdades descritas por Bauman (2001). En cualquier caso estamos hablando de la emergencia de iniciativas locales y comiunitarias en el contexto de la globalización neoliberal, coincidiendo con las aportaciones de Williamson, Imbroscio, y Alperovitz (2002), y con las perspectivas expuestas por Barkin (2009), y Barkin y Baron (2005).

Si bien encontramos población con formación también muy diversa, una cuarta parte de la población estudiada son personas con Estudios Universitarios. Y más concretamente, los principales contextos de origen de los participantes son personas del ámbito de los servicios sanitarios y sociales, los más golpeados por la crisis. Como vemos, se produce también una conexión entre los universitarios y estas iniciativas sociales alternativas. Recordemos los antecedentes expuestos por Miranda (2004) sobre esta conexión, que ya se daba en los 'Toynbee Hall', y los 'settlement movement', o más actualmente, en la 'Residencia Flora Tristán' de la Universidad Pablo de Olavide.

Profundizando en estas conclusiones, vemos que se utilizan estas actividades comunitarias como si de un "mercado alternativo" al hegemónico se tratase, siguiendo las ideas anteriormente expuestas (Rauch y Schleicher 2015; Botsman y Rogers 2010; Algar 2007) o las argumentadas por Bretos y Marcuello (2017). Y que además tienen mucho sentido en el contexto de la Teoría del Decrecimiento de Latouche (2007). Al mismo tiempo y de forma complementaria se da una identificación con el concepto de "bien común" (Ostrom 2003). Donde aparecen porcentajes muy elevados de satisfacción y de identificación con los valores comunes. Entendemos pues estas iniciativas comunitarias como una forma de mercado o economía alternativa, que se sustentan en el principio de bien común y que se impulsan a través de la satisfacción e identificación con los valores que representan. En estos contextos de 'mercado' cobra especial interés la construcción de una 'confianza social' tal y como la describen Sabatini, Modena, y Tortia (2014). Entendemos que se trata de un 'mercado alternativo' que no solo busca un mercadeo, sino también alcanzar objetivos de beneficio público apoyados por preferencias altruistas (Borzaga, Depedri y Tortia, 2010).

Hoy en día es una reivindicación fuerte la recuperación de los bienes comunes. No solo los ríos, la tierra, los bosques...etc., lo que en la Inglaterra precapitalista llamaban "commons" ya en 1.217 (Linebangh 2013). Hoy se reivindicarían también los ferrocarriles, la electricidad, la telefonía, internet..... y por supuesto educación, salud, servicios sociales, etc. 
Las principales formas de acceso a estas actividades son a través de familiares y amistades. Nos evoca las características de los "círculos de confianza" (Botsman y Rogers 2010; Algar 2007). Recordemos también las aportaciones al respecto de las investigaciones de Fleischman et al. (2010), o las realizadas por Ostrom (2010) sobre la reputación, confianza y reciprocidad. Precisamente el hecho de la participación basada en la confianza es primordial, y según los datos obtenidos, se combinan con una alto nivel de criticismo interno; los participantes son muy críticos hacia las formas de gestión y de organización de las iniciativas, lo que demuestra una alta madurez en los procesos de participación e implicación con las iniciativas. Otro elemento relacionado con las formas de participación en las actividades y con la implicación en las mismas, es la cercanía: Un alto grado de acceso o proximidad física al espacio en el que se desarrolla la actividad de la que se trate. En relación a estas afirmaciones, cobra sentido la Teoría del Capital Social de Putnam (2000), y la importancia de los vínculos que estas iniciativas comunitarias crean y refuerzan.

Resulta de interés descubrir que los participantes no ven con claridad la relación global-local, la relación entre su actividad comunitaria local y los elementos más globales que la definen o la influyen. Como hemos indicado antes, la principal relación de los participantes con estas iniciativas locales tiene un fundamento económico originado en situaciones de necesidad. Esta base económica, que tiene elementos mucho más globales, se pierde y no se ve con claridad dentro de las iniciativas. Encontramos una disfunción global-local: No observan la conexión entre lo global y lo local, o cómo los condicionantes globales afectan a sus actividades locales. Estos elementos nos recuerdan las aportaciones de Hamzaoui (2005) en referencia precisamente al concepto de 'territorialización'. Noya y Rodriguez (2010) atribuyen este refuerzo de lo local, precisamente a la dureza y frialdad de las condiciones globales, más deshumanizadas.

Los encuestados nos dicen que estas respuestas comunitarias están mucho más relacionadas con el fracaso del Estado, que con el del Mercado. Parece que salvan de las situaciones de carencia a los agentes que operan a niveles más globales (mercado) que a aquellos que se visualizan con mayor proximidad o a nivel local (la administración de lo público). Tan sólo una quinta parte de la muestra considera estas iniciativas como una respuesta contra la polarización social y económica. Esto nos refiere al problema de la legitimidad de Weber (1968) y de O'Connor (1973) que se entiende especialmente dentro de un contexto de desigualdad alimentado en las formas de globalización económica: el concepto de 'deslegitimación por sobredemanda' de Mishra (1999). Estos planteamientos también los encontramos en las aportaciones de Noya y Rodriguez (2010), Offe (1996), o incluso Hessel (2011).

En referencia a las características de las personas que se vinculan a este tipo de actividades comunitarias, encontramos una representación heterogénea en cuanto a la edad. La variable de edad guarda relación con los contextos de participación comunitaria. La edad se vincula a la participación en contextos distintos: Por ejemplo, las personas mayores se concretan en mayor número en actividades comunitarias de provisión de servicios, como es el caso de los Bancos del tiempo.

Tras analizar las características de los movimientos comunitarios que se desarrollan en relación a la nueva realidad socioeconómica tras el inicio de la crisis 
económica en estos últimos años, podemos considerar válida la hipótesis principal: Los movimientos de base comunitaria suponen una ayuda a aspectos económicos de las familias e individuos y toman fuerza en situaciones de crisis económicas.

Este estudio también presenta algunas limitaciones. El estudio sólo se centra en iniciativas en el contexto de una sociedad desarrollada. Sería muy interesante generar investigaciones que abarcasen iniciativas comunitarias en distintos contextos internacionales, en países desarrollados y en desarrollo. Otra de las limitaciones es precisamente la limitación que la metodología cuantitativa presenta. Si bien nos permite estimar la extensión del fenómeno estudiado, sería también de interés profundizar en futuras investigaciones con metodología cualitativa, o al menos sensible a parámetros más subjetivos como puedan ser las Historias de Vida.

En síntesis, podríamos decir que tras un fracaso del sistema, en forma de crisis económicas, social, institucional,...se generan movimientos opuestos y contestatarios contra los que se consideran causantes de la situación de crisis. Movimientos opuestos a las formas de gestión o administración (contra lo público); movimientos en contra de los poderes económicos (del mercado hegemónico y tradicional). Estos movimientos intentan reorganizarse desde el bien común, desde la economía colaborativa, utilizando las potencialidades de los sujetos, muchos de ellos con formación universitaria, que han sido dejados fuera (excluidos) del juego social y económico a través del desempleo. Movimientos que al tiempo satisfacen necesidades sociales y económicas no satisfechas por otras vías. Pero con una visión muy centrada en lo local, lo inmediato y lo cercano. Es como si se tratara de un comunitarismo aislado, en el que no se conecta con los elementos estructurales que operan a nivel global y que son causantes y alimentadores de las condiciones de desempleo, necesidad, etc...que generaron precisamente las alternativas comunitarias. Lo comunitario queda "territorializado" (Hamzaoui 2005) en lo local, con respuestas locales centradas en lo cotidiano y lo inmediato, mientras que las reglas económicas que lo generan, quedan a salvo en lo global, en lo lejano, expresado en un contexto de globalización económica neoliberal.

\section{Referencias bibliográficas}

Algar, R. (Abril de 2007) Collaborative Consumption. Leisure Report, pp. 16-17.

Barkin, D. (2001) Neoliberalism and sustainable popular development. En A. O. Henry Veltmeyer, Transcending Neoliberalism: Community Based Development in Latin America (pp. 184-204). Bloomfield, CT: Kumarian Press.

Barkin, D. (2009) Principles for constructing alternative socio-economic organizations: Lessons learned from working outside institutional structures. Review of Radical Political Economics, Vol. 41, No 3, pp. 372-379.

Barkin, D. y Barón, L. (2005) Constructing alternatives to globalisation: Strengthening tradition through innovation. Development in Practice, Vol. 15, No 2, pp. 175-185.

Bauman, Z. (2001) La globalización: consecuencias humanas. Méjico: Fondo de Cultura Económica.

Borzaga, C., Depedri, S. y Tortia, E. (2010) The Role of Cooperative and Social Enterprises: A Multifaceted Approach for an Economic Pluralism. Euricse Working Papers, № 9, pp. 1-20. 
Botsman, R. y Rogers, R. (2010) What's mine is yours: The rise of Collaborative Consumption. New York: HarperBusiness.

Bretos, I. y Marcuello, C. (2017) Revisiting globalization challenges and opportunities in the development of cooperatives. Annals of Public and Cooperative Economics, Vol. $88, \mathrm{~N}^{\circ} 1$, pp. 47-73.

Castel, R. (1997) Las metamorfosis de la cuestión social. Barcelona: Paidós.

Díaz, C. (2003) La formación comunitaria como generadora de participación y transformación social. Anuario de Filosofía, Psicología y Sociología, No 6, pp. 241-252.

Fleischman, F., Boenning, K., Garcia-Lopez, G., Mincey, S., Schmitt-Harsh, M., Daedlow, K., y otros. (2010) Disturbance, response, and persistence in self-organized forested communities: Analysis of robustness and resilience in five communities in Southern Indiana. Ecology and Society, Vol. 15, № 4, Open access (art.9).

Hamzaoui, M. (2005) Trabajo Social Territorializado. Las transformaciones de la acción pública en la intervención social. Valencia: NAU Libres.

Harvey, D. (2007) Breve historia del neoliberalismo. Madrid: Akal.

Hessel, S. (2011) Indignaos. Barcelona: Destino.

Krugman, P., Wells, R. y Graddy, K. (2015) Fundamentos de Economía. Barcelona: Reverté.

Latouche, S. (2007) Sobrevivir al desarrollo. De la descolonización del imaginario económico a la construcción de una sociedad alternativa. Madrid: Icaria.

Lizárraga, C. (2013) El Índice de Gini: la desigualdad a la palestra. EXtoikos, No 10, pp. 6769.

Miranda, M. (2004) De la caridad a la ciencia. Pragmatismo, Interaccionismo Simbólico y Trabajo Social. Zaragoza: Mira Editores.

Mishra, R. (1999) Globalization and the Welfare State. Cheltenham: Elgar.

Noya, J. y Rodríguez, B. (2010) Teorías sociológicas de la globalización. Madrid: Tecnos.

OCDE (16 de Febrero de 2016b) Poverty rate (indicator). Obtenido de DOI: $10.1787 / 0$ fe 1315 d-en .

OCDE (2015) Society at a Glance 2014. OECD Social Indicators. Paris: OECD Publishing.

OCDE (16 de Febrero de 2016a) Income inequality (indicator). Obtenido de DOI: $10.1787 / 459$ aa7f1-en.

O'Connor, J. (1973) The Fiscal Crisis of the State. New York: St. Martin's Press.

Offe, C. (1996) Modernity and State: East, West. Cambridge: MIT Press.

Ortiz, E. (2010) Derecho a la ciudad, producción social y gestión participativa del hábitat. La promoción de iniciativas comunitarias incluyentes en la Ciudad de México. Habitat y Sociedad, $\mathrm{N}^{\mathrm{o}} 1$, pp. $55-70$.

Ostrom, E. (2003) How types of goods and property rights jointly affect collective action. Journal of Theoretical Politics, Vol. 15, No 3, pp. 239-270.

Ostrom, E. (2010) Analyzing collective action. Agricultural Economics, Vol. 41, No 1, pp. 155-166.

Putnam, R. (2000) Bowling Alone: The Collapse and Revival of American Community. New York: Simon and Schuster.

Rauch, D. y Schleicher, D. (2015) Like Uber, But for Local Governmental Policy: The Future of Local Regulation of the 'Sharing Economy'. George Mason Law \& Economics Research Paper, Vol. 15, № 1, pp. 1-60.

Sabatini, F., Modena, F. y Tortia, E. (2014) Do cooperative enterprises create social trust? Small Business Economics, Vol. 42, N 3, pp. 621-641.

Sennett, R. (2006) La cultura del nuevo capitalismo. BArcelona: Anagrama. 
Smith, R. (1999) Settlements and neighborhood centers. En T. Mizrahi, \& L. Davis, Encyclopedia of Social Work. Oxford University Press.

Stiglitz, J. (2012) El precio de la desigualdad. . Madrid: Taurus.

Weber, M. (1968) Economy and Society. En Conceptual Exposition (pp. 956-1005). New York: Bedminister Press.

Williamson, T., Imbroscio, D. y Alperovitz, G. (2002) Making a Place for Community: Local Democracy in a Global Era. New York: Routledge.

\section{Anexo I: Variables y sus estadísticos descriptivos.}

\begin{tabular}{|c|c|c|c|c|}
\hline Pregunta del cuestionario & Variables & $\mathrm{N}$ & Media & Desv. típ. \\
\hline 0 & Contextos de participación comunitaria & 82 & 3,46 & 1,178 \\
\hline 1 & Sexo & 82 & 1,63 & ,485 \\
\hline 2 & Edad & 82 & 2,63 & 1,291 \\
\hline 3 & Estado civil & 82 & 2,06 & ,998 \\
\hline 4 & Nivel de formación & 82 & 5,04 & 2,146 \\
\hline \multirow{2}{*}{5} & Nacionalidad & 82 & 1,01 & 110 \\
\hline & Nacionalidad Española & 82 & 1,01 &, 110 \\
\hline 6 & Tipo de vivienda & 82 & 1,54 & ,789 \\
\hline 7 & Carga familiar & 81 & 1,93 & 1,170 \\
\hline 8 & Realización de actividades voluntarias & 82 & 1,71 & 1,262 \\
\hline 9 & $\begin{array}{l}\text { Frecuencia con la que acude a las } \\
\text { actividades comunitarias }\end{array}$ & 80 & 1,67 &, 742 \\
\hline 10 & $\begin{array}{l}\text { Tiempo durante el que permanece en la } \\
\text { actividad }\end{array}$ & 80 & 1,85 & 1,192 \\
\hline 11 & $\begin{array}{l}\text { Desde cuándo conoce estas actividades } \\
\text { comunitarias }\end{array}$ & 79 & 1,67 & ,473 \\
\hline 12 & $\begin{array}{l}\text { Fuente de conocimiento de estas } \\
\text { actividades comunitarias }\end{array}$ & 82 & 5,82 & 3,120 \\
\hline 13 & $\begin{array}{l}\text { Actividades comunitarias en las que } \\
\text { participa }\end{array}$ & 78 & 1,46 &, 502 \\
\hline 14 & Opinión general sobre estas actividades & 81 & 3,51 &, 551 \\
\hline 15 & $\begin{array}{l}\text { Opinión sobre la percepción de la } \\
\text { sociedad sobre estas actividades }\end{array}$ & 81 & 3,21 & ,607 \\
\hline \multirow{6}{*}{16} & $\begin{array}{l}\text { Considera que existe adecuada } \\
\text { información para poder participar }\end{array}$ & 81 & 1,80 & ,401 \\
\hline & 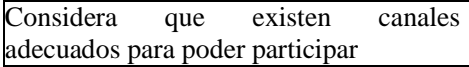 & 77 & 1,78 & ,417 \\
\hline & $\begin{array}{l}\text { Considera que estas actividades forman } \\
\text { y educan en determinados valores }\end{array}$ & 80 & 1,96 &, 191 \\
\hline & $\begin{array}{l}\text { Considera que existe motivación para } \\
\text { seguir participando, o para invitar a } \\
\text { participar a otros }\end{array}$ & 80 & 1,95 & ,271 \\
\hline & $\begin{array}{l}\text { Considera que } \quad \text { existe } \quad \text { buena } \\
\text { coordinación para su funcionamiento }\end{array}$ & 81 & 1,88 & ,331 \\
\hline & Considera que existe un buen horario & 81 & 1,89 & ,316 \\
\hline \multirow{3}{*}{17} & $\begin{array}{l}\text { Considera que estas actividades } \\
\text { responden a un tipo de ideología o forma } \\
\text { de entender el mundo concreto }\end{array}$ & 82 & 1,82 & ,389 \\
\hline & $\begin{array}{l}\text { Considera que estas actividades suponen } \\
\text { una respuesta alternativa a las cuestiones } \\
\text { económicas dominantes }\end{array}$ & 81 & 1,83 &, 380 \\
\hline & $\begin{array}{l}\text { Considera que estas actividades suponen } \\
\text { una forma de contestación a las líneas } \\
\text { políticas dominantes }\end{array}$ & 81 & 1,80 & ,401 \\
\hline
\end{tabular}




\begin{tabular}{|c|c|c|c|c|}
\hline 18 & $\begin{array}{l}\text { Opinión sobre la relación de estas } \\
\text { actividades con la actual situación de } \\
\text { desempleo }\end{array}$ & 79 & 1,39 &, 517 \\
\hline 19 & Considera la actividad como mercado & 80 & 2,45 & ,593 \\
\hline 20 & $\begin{array}{l}\text { Considera la actividad como generadora } \\
\text { de beneficio económico }\end{array}$ & 77 & 2,52 & ,718 \\
\hline 21 & $\begin{array}{l}\text { Opinión sobre quién son los agentes de } \\
\text { control }\end{array}$ & 75 & 3,51 & 1,045 \\
\hline \multirow{4}{*}{22} & $\begin{array}{l}\text { Considera la actividad como respuesta al } \\
\text { fracaso del Mercado }\end{array}$ & 76 & 1,72 & ,450 \\
\hline & $\begin{array}{l}\text { Considera la actividad como respuesta al } \\
\text { fracaso del Estado (Administración } \\
\text { Pública) }\end{array}$ & 76 & 1,58 & ,497 \\
\hline & $\begin{array}{l}\text { Considera la actividad como respuesta al } \\
\text { fracaso de las iniciativas sociales }\end{array}$ & 76 & 1,88 & ,325 \\
\hline & $\begin{array}{l}\text { Considera que esta actividad no surge } \\
\text { como respuesta a ningún fracaso }\end{array}$ & 76 & 1,64 & ,482 \\
\hline \multirow{4}{*}{23} & Considera la iniciativa como autónoma & 75 & 1,84 & ,369 \\
\hline & $\begin{array}{|lll|}\begin{array}{l}\text { Considera la iniciativa como } \\
\text { autosuficiente }\end{array} & & \\
\end{array}$ & 74 & 1,82 & 383 \\
\hline & $\begin{array}{l}\text { Considera que existe una diversificación } \\
\text { productiva en la iniciativa }\end{array}$ & 70 & 1,71 & ,455 \\
\hline & $\begin{array}{l}\text { Considera que la iniciativa supone una } \\
\text { gestión sostenible de los recursos }\end{array}$ & 75 & 1,79 & ,412 \\
\hline \multirow{3}{*}{24} & $\begin{array}{l}\text { Considera la iniciativa como una } \\
\text { propuesta para superar la crisis }\end{array}$ & 77 & 1,61 & ,491 \\
\hline & \begin{tabular}{|l} 
Considera la iniciativa implica un \\
aumento de la participación social
\end{tabular} & 79 & 1,92 & 267 \\
\hline & $\begin{array}{l}\text { Considera que la iniciativa aumenta la } \\
\text { acción local }\end{array}$ & 77 & 1,91 & ,289 \\
\hline 25 & $\begin{array}{l}\text { Considera estas iniciativas como } \\
\text { respuesta contra la polarización social y } \\
\text { económica }\end{array}$ & 77 & 1,78 & ,417 \\
\hline 26 & $\begin{array}{l}\text { Considera estas iniciativas como } \\
\text { respuesta ante el empeoramiento de las } \\
\text { condiciones ambientales }\end{array}$ & 79 & 1,65 & ,481 \\
\hline \multirow{8}{*}{27} & $\begin{array}{l}\text { Considera a las personas que realizan } \\
\text { estas actividades como tradicionales o } \\
\text { alternativas }\end{array}$ & 77 & 1,77 & ,426 \\
\hline & $\begin{array}{l}\text { Considera a las personas que realizan } \\
\text { estas actividades como aburridas o } \\
\text { divertidas }\end{array}$ & 78 & 1,95 & ,222 \\
\hline & $\begin{array}{l}\text { Considera a las personas que realizan } \\
\text { estas actividades como pasivas o activas }\end{array}$ & 79 & 1,96 & ,192 \\
\hline & $\begin{array}{l}\text { Considera a las personas que realizan } \\
\text { estas actividades como no implicadas o } \\
\text { concienciadas }\end{array}$ & 75 & 1,92 & ,273 \\
\hline & $\begin{array}{l}\text { Considera a las personas que realizan } \\
\text { estas actividades como estresadas o sin } \\
\text { estrés }\end{array}$ & 75 & 1,83 & ,381 \\
\hline & $\begin{array}{l}\text { Considera a las personas que realizan } \\
\text { estas actividades como malas o buenas }\end{array}$ & 75 & 1,88 & ,327 \\
\hline & $\begin{array}{l}\text { Considera a las personas que realizan } \\
\text { estas actividades como avariciosas o } \\
\text { generosas }\end{array}$ & 77 & 1,94 & ,248 \\
\hline & $\begin{array}{l}\text { Considera a las personas que realizan } \\
\text { estas acitivdades como egoistas o } \\
\text { altruistas }\end{array}$ & 77 & 1,86 & ,352 \\
\hline
\end{tabular}




\begin{tabular}{|c|c|c|c|c|}
\hline & $\begin{array}{l}\text { Considera a las personas que realizan } \\
\text { estas actividades como insolidarias o } \\
\text { solidarias }\end{array}$ & 78 & 1,92 & ,268 \\
\hline 28 & $\begin{array}{l}\text { Sentimiento al vincularse en estas } \\
\text { actividades }\end{array}$ & 77 & 1,96 & ,195 \\
\hline 29 & $\begin{array}{l}\text { Recomendación de la actividad a otras } \\
\text { personas }\end{array}$ & 80 & 1,11 & ,356 \\
\hline 30 & $\begin{array}{l}\text { Nivel de identificación con los valores } \\
\text { que representan estas actividades }\end{array}$ & 79 & 3,52 & ,658 \\
\hline 31 & $\begin{array}{l}\text { Tipos de intereses que dan lugar a estas } \\
\text { iniciativas }\end{array}$ & 80 & 1,98 & ,389 \\
\hline 32 & $\begin{array}{l}\text { Tipos de esfuerzos que dan lugar a estas } \\
\text { iniciativas }\end{array}$ & 80 & 1,95 & ,314 \\
\hline 33 & $\begin{array}{l}\text { Cercanía de estas actividades respecto al } \\
\text { domicilio }\end{array}$ & 82 & 1,48 &, 549 \\
\hline 34 & Residencia en el barrio & 80 & 1,46 & ,502 \\
\hline 35 & $\begin{array}{l}\text { Considera que estas actividades tienen } \\
\text { capacidad de influencia en la } \\
\text { Administración }\end{array}$ & 76 & 1,89 & ,624 \\
\hline 36 & $\begin{array}{l}\text { Considera que estas actividades tienen } \\
\text { capacidad de influencia en la Empresa }\end{array}$ & 75 & 1,57 & ,701 \\
\hline 37 & $\begin{array}{l}\text { Consideración sobre el nivel de } \\
\text { identificación de la Administración } \\
\text { Pública respecto a estas actividades }\end{array}$ & 72 & 2,03 & ,750 \\
\hline 38 & $\begin{array}{l}\text { Considera que existen unos valores } \\
\begin{array}{l}\text { compartidos por los implicados y } \\
\text { participantes }\end{array}\end{array}$ & 79 & 1,20 & ,404 \\
\hline 39 & $\begin{array}{l}\text { Considera que existen unos intereses } \\
\text { compartidos por los implicados y } \\
\text { participantes }\end{array}$ & 79 & 1,59 & ,494 \\
\hline 40 & $\begin{array}{l}\text { Considera que existe deseo de extender } \\
\text { esta experiencia y formar a otros en ella }\end{array}$ & 79 & 1,49 & ,503 \\
\hline 41 & $\begin{array}{l}\text { Valoración de la participación en la } \\
\text { actividad. }\end{array}$ & 81 & $\begin{array}{c}\text { Variable } \\
\text { mediante anál }\end{array}$ & $\begin{array}{l}\text { trabajada } \\
\text { Likert. }\end{array}$ \\
\hline \multirow{6}{*}{42} & $\begin{array}{l}\text { Considera que estas iniciativas fomentan } \\
\text { un sentimiento de pertenencia a una } \\
\text { comunidad }\end{array}$ & 78 & 1,06 &, 247 \\
\hline & $\begin{array}{l}\text { Considera que estas iniciativas fomentan } \\
\text { el estrechamiento de lazos comunitarios }\end{array}$ & 78 & 1,06 & ,247 \\
\hline & $\begin{array}{l}\text { Considera que estas iniciativas están } \\
\text { influenciadas por políticas sociales y } \\
\text { económicas locales }\end{array}$ & 69 & 1,49 &, 504 \\
\hline & $\begin{array}{l}\text { Considera que estas iniciativas están } \\
\text { influenciadas por políticas sociales y } \\
\text { económicas nacionales }\end{array}$ & 69 & 1,90 & ,304 \\
\hline & $\begin{array}{l}\text { Considera que estas iniciativas están } \\
\text { influenciadas por políticas sociales y } \\
\text { económicas internacionales }\end{array}$ & 69 & 1,87 & ,339 \\
\hline & $\begin{array}{l}\text { Considera que estas políticas no están } \\
\text { influidas }\end{array}$ & 69 & 1,57 & ,499 \\
\hline 43 & Situación económica & 75 & 2,33 & 1,417 \\
\hline 44 & Nivel de ingresos & 69 & 1,49 & 504 \\
\hline 45 & Situación laboral actual & 78 & 3,60 & 1,399 \\
\hline 46 & Situación laboral hace 3 años & 78 & 3,10 & 1,517 \\
\hline 45 y 46 & Cambios en la situación laboral & 75 & 2,20 & 1,151 \\
\hline 47 & Rama de actividad profesional & 55 & 13,60 & 5,349 \\
\hline
\end{tabular}

Fuente: Elaboración propia. 